six month attachment to a learning disabilities unit. Monitoring was by means of written records of all clinical contracts. Specially designed forms were used which encouraged a problem-orientated approach, recording interventions made and outcome. Evaluation occurred during consultant and pharmacist supervision, allowing changes in clinical approach to be introduced. The limitation of too close an adherence to a medical model were highlighted and the benefits felt of an outsider commenting on prescribing habits. Inter-disciplinary discussions were facilitated by the audit forms (in the community setting case notes are often absent) and the desire to measure outcome of medical interventions led to requests for information about client behaviour from nursing staff in an objective form, such as the charting of events or the use of rating scales. The audit highlighted differences in multidisciplinary involvement between long-stay in-patient and hostel patients. A medication review confirmed a large reduction in the use of neuroleptics for behaviour control had been achieved without deterioration in behaviour. Appraisal of the range of experience gained by the trainee was facilitated, so that deficiencies in training could be rectified. The benefits of a self-audit exercise merits advertisement to colleagues.

J.L. Gillow

R. BANKS

P. Pratt

Brunswick House

299 Glossop Road

Sheffield $S 102 H L$

\section{Environmental change and violent incidents}

\section{DeAR SiRS}

I read with great interest the paper on environmental change and violent incidents (Psychiatric Bulletin, $1992,16,489-490)$. The conclusion that "the reduction in violent incidents ... was primarily due to change of environment" needs to be challenged. The definition of violent incidents was not specified. Data on the validity and reporting reliability of violent incidents were not provided. For example, it may be that fewer staff in hostels or only 14 hour staffing in homes may result in a poor reporting reliability for violent incidents. A number of other factors need to be considered and have been summarised elsewhere (Shah et al, 1991). These include demographic characteristics of nonviolent patients, activity patterns (admission rates, length of stay and bed occupancy) and staff attitude, training and nature (temporary or permanent) in all three settings. Unless consideration is given to the above array of factors the conclusion becomes weak. Having said this, the study in question has attempted to address the important issue of changing environment for our patients, which is occurring at increasing frequency in the modern era of community care.

\section{St Vincent's Hospital Clinical School University of Melbourne \\ Melbourne, Australia}

AjIT SHah

\section{References}

Shah, A. K., Fineberg, N. A. \& James, D. V. (1991) Violence among psychiatric inpatients. Acta Psychiatrica Scandinavica, 84, 304-309.

\section{Reply}

DEAR SIRS

I thank Dr Shah for his comments, but disagree that the conclusion is weak. Violent incidents are documented when an act causes or is intended to cause physical harm to a third party. Although validity and reporting reliability were not specified, the same staff rated incidents before and after transfer. There is no reason to suppose that their criteria or reporting reliability suddenly changed. Within the houses/ hostels the average staff/patient ratio remained comparable to that of the ward. Houses are unstaffed between the hours of 21.00 to $07.00 \mathrm{hrs}$; this is the period when very little violence occurs, which is also acknowledged by Dr Shah, and is unlikely to significantly reduce reporting reliability.

The study suggested the reduction in violent incidents was due to the change of environment. The other factors mentioned by Dr Shah fall within the definition of environment. A number of interrelated variables were considered in the original paper, but I am grateful to Dr Shah for emphasising the huge array of factors, which obviously, require consideration. Quantifying the myriad of influencing factors appertaining to "the environment" would require an abundance of data which was not available.

\section{Walton Hospital}

C.W. Rusius

\section{Chesterfield S40 $3 \mathrm{HN}$}

\section{Use of antidepressants by child psychiatrists}

DEAR SIRS

I was interested to read Bramble \& Dunkley's article about the prescribing habits of child psychiatrists (Psychiatric Bulletin, 1992, 16, 396-398), but was perplexed by their apparently interchangeable use of the terms "antidepressant" and "tricyclic antidepressant" (TCA). In their opening discussion they state that there has never been a survey looking "specifically" at TCA use; the description of their 
study method then talks about antidepressant use in general-but their findings once more specify TCA use only. One wonders whether the psychiatrists were asked about TCA use or about the use of antidepressants in general; if the former was the case then it might explain the relatively rare reports of use of drugs other than the TCAs, even in adolescents.

Also, although I realise there must be a long "lead time" before publication, it seems strange for an article to quote from a British National Formulary which has been out of date for more than a year - and to state, in July 1992, that fluvoxamine and fluoxetine are "the latest 5-HT re-uptake inhibitors"!

St Mary's Hospital

T.H. LEIGH

London W2 INY

\section{Reply}

DeAR Sirs

We are concerned that the terminology concerning antidepressants employed in our paper led to some perplexity on Dr Leigh's part. In our prescription survey we sharply differentiated between the tricyclic (or related) antidepressants and other agents which may also be used in given conditions which are indications for the tricyclics (lithium, carbamazepine, MAOIs, etc). Upon reflection it may have been more correct to use the term "monoamine re-uptake inhibitor" (MARI) in preference to "tricyclic antidepressant"; however, we believe that the latter term is still a widely used generic term for this admittedly increasingly heterogeneous group of drugs. Whether they are "antidepressants" or "antidepressives" is quite another matter! None of the 248 respondents to the survey indicated similar problems with our terminology, therefore, for the purpose of interpretating our results the term antidepressant is synonymous with term tricyclic "or related" agent unless stated otherwise.

Regarding our description of fluoxetine and fluvoxamine as "the latest 5-HT re-uptake inhibitors", we acknowledge that they may well be rather old news to most clinicians yet in the gentle, careful groves of British child psychiatry they are indeed new and possibly rather threatening commodities. Remember, we discovered that those old work horses amitriptyline and imipramine are still far and away the most popular "tricyclic" antidepressants prescribed by the specialty.

D. BRAMBLE

Clinical Sciences Building

Leicester Royal Infirmary

Leicester LE2 7LX

\section{St Charles Centre}

\section{Dear Sirs}

We are writing to correct some errors of fact in the letter from T.D. Scannell (Psychiatric Bulletin, 1992, 16, 509). This letter makes a number of comments about St Charles Youth Treatment Centre, now St Charles Centre, part of the Youth Treatment Service (YTS), which merit a reply.

The letter suggests that management are intending to employ more psychologists. This is not the case: the complement for psychologists at St Charles numbers two (as it does at the Glenthorne Centre in Birmingham, also part of the YTS). With regard to the role of psychiatrists, there are arrangements in hand for formalising service contracts that will benefit both Centres by having psychiatrists who will participate in the work of multidisciplinary teams. The role of psychiatrists, like their professional colleagues, will be to contribute to clinical work, research, and training within the YTS. This is a long way from the monitoring of medication noted in your correspondent's letter, and will ensure the highest quality of service for the young people entrusted to the care of the YTS.

With regard to clinical autonomy, it is recognised within the YTS that clinicians have their professional codes of conduct and must act in the best interest of their client. It is not the policy of the YTS to seek to compromise clinical responsibility in any way.

There has not been a political directive that has changed the ethos at the St Charles Centre. Further, despite your correspondent's comments, the ethos at St Charles is not behavioural. (In any case, we would wish to resist the stereotype that behavioural practice has an emphasis on care and control: good behavioural practice is both psychotherapeutic and growth-enabling.)

Youth Treatment Service

A. Mackin

St Charles Centre

Brentwood, Essex

CM144SJ

\section{Doctors in management}

DeAr Sirs

There is no doubt that management education should form part of the training of every clinician, as stated by Gadd \& England (Psychiatric Bulletin, August 1992, 16, 484-485).

Doctors have been encouraged to be directly involved with the NHS management process (Griffiths Report, 1983). This report generated the clinical directorate concept for unit management. Exposure to management development aims at 